\title{
A IMPORTÂNCIA DA ESCUTA NO CUIDADO DE ENFERMAGEM
}

\author{
Simone de Oliveira Camilloㄹ, Fabiana Tavolaro Maiorino²
}

\begin{abstract}
RESUMO: O objetivo deste estudo foi investigar a percepção de pacientes quanto à assistência de Enfermagem calcada numa escuta eficiente. Trata-se de um estudo exploratório, com metodologia qualitativa e referencial teórico no Pensamento Complexo de Morin. A investigação foi feita com dez pacientes internados em um hospital público em Santo André-São Paulo. Os dados foram coletados em agosto de 2008, por meio da técnica de Entrevista Individual em Profundidade, e analisados por meio da técnica de Análise de Conteúdo. As categorias resultantes foram $O$ ato de escutar comprometido pela falta de tempo e de pessoas na equipe de enfermagem; A escuta do profissional de enfermagem: propiciando ao doente a sensação de ser compreendido; $O$ ato de escutar com disponibilidade da equipe de enfermagem. A escuta sensível é essencial para a compreensão da complexidade humana e assistência de enfermagem significativa.
\end{abstract}

PALAVRAS-CHAVE: Percepção; Assistência de enfermagem; Cuidado.

\section{THE IMPORTANCE OF LISTENING IN NURSING CARE}

ABSTRACT: This study aimed to investigate patients' perception regarding Nursing care grounded in efficient listening. It is an exploratory study, with a qualitative methodology, and uses Morin's "Complex Thought" as its theoretical framework. The investigation was undertaken with ten patients hospitalized in a public hospital in Santo André in São Paulo. The data was collected in August 2008, using the technique of Individual In-depth Interview, and was analyzed using the technique of Content Analysis. The resulting categories were: The act of listening compromised by lack of time and staff in the nursing team; The professional nurse's listening: affording the patient the feeling of being understood; The act of listening with availability of the nursing team. Sensitive listening is essential for the understanding of human complexity and for meaningful nursing care.

KEYWORDS: Perception; Nursing care; Care.

\section{LA IMPORTANCIA DE ESCUCHAR EN EL CUIDADO DE ENFERMERÍA}

RESUMEN: El objetivo de este estudio fue investigar la percepción de pacientes cuanto a la asistencia de Enfermería basada en una escucha eficiente. Es un estudio exploratorio, de metodología cualitativa y referencial teórico en el Pensamiento Complejo de Morin. La investigación fue hecha con diez pacientes internados en un hospital público en Santo André, São Paulo. Los datos fueron obtenidos en agosto de 2008, por medio de la técnica de Entrevista Individual en Profundidad, y analizados por la técnica de Análisis de Contenido. Las categorías resultantes fueron El acto de escuchar comprometido por la falta de tiempo y de personas en el equipo de enfermería; La escucha del profesional de enfermería: posibilitando al enfermo la sensación de ser comprendido; El acto de escuchar con disponibilidad del equipo de enfermería. La escucha sensible es esencial para la comprensión de la complejidad humana y asistencia de enfermería significativa.

DESCRIPTORES: Percepción; Asistencia de enfermería; Cuidado.

${ }^{1}$ Enfermeira. Doutora em Ciências. Professora do Curso de Graduação em Enfermagem da Faculdade de Medicina da Fundação do ABC, Santo André - São Paulo.

${ }^{2}$ Psicóloga. Mestre em Comunicação e Semiótica 


\section{INTRODUÇÃO}

A capacidade de comunicação promoveu a criação de um verdadeiro tesouro de signos, de um mundo de significações e representações, que ao longo dos séculos foram transmitidos como herança através das gerações. Assim, cada homem que nasce herda, de alguma forma, toda a cultura que o precedeu e a transmite, por meio da comunicação/linguagem, aos seus contemporâneos. Através desse sistema de símbolos, próprio de cada cultura, a realidade é explicada por algum sistema de coerência lógica, dotada de significação e possibilitadora de sentidos ${ }^{(1)}$.

No mundo de hoje, globalizado e hipercomunicacional, é cada vez mais evidente a necessidade do acesso à informação e a busca por visibilidade social, que gera um processo crescente de individualização e um universo comunicacional permeado de ruídos. Esse contexto cria inúmeras dificuldades nas relações intersubjetivas, entre elas o ato de escutar. Para que possamos adentrar nessa questão específica faz-se necessário recorrermos a algumas definições:

Escutar - [Do Latim auscutare]. Tornar-se ou estar atento para ouvir, dar ouvidos a, aplicar o ouvido com atenção para perceber ou ouvir; atender aos conselhos de espiar; espionar; prestar atenção para ouvir alguma coisa, exercer ou aplicar o sentido da audição ${ }^{(2: 803)}$

Ouvir - [Do latim audire]. Perceber, entender sons pelo sentido da audição, dar atenção, atender ${ }^{(2: 1465)}$.

Escutar não se limita apenas ao ouvir enquanto captação de sons (sensações), mas se refere à busca de apreensão do sentido do dizer. Sugere aproximação (auscutare), ouvir de perto, ouvir o que está dentro do outro; também é compreendido como atender e recolher o que foi dito. Para escutar é necessário haver uma doação, no sentido de se dispor inteiramente da escuta do que está sendo dito, é escutando que nos abrimos para o mundo e para os outros, pois se trata de um dizer que nos remete a um mundo, e não apenas a um mero falar ${ }^{(1)}$.

Num mundo hipermidiático, que nos bombardeia cotidianamente de informações e ruídos, e que também exige exposição constante para nos sobressairmos no universo social, ficamos mais propensos a falar do que a escutar. Habituamo-nos a interromper, a qualquer pretexto, as pessoas que estão falando. Diante disso, percebe-se que o ato de falar é considerado algo muito positivo em nossa sociedade, contrariamente ao ato de escutar. Quando alguém nos fala, em vez de escutar até o fim o que se tem a dizer, começamos a comparar quase que imediatamente, o que está sendo dito com nossas ideias e referenciais prévios. Portanto, nossa dificuldade de escutar pode ser explicada, pelo fato de que cada indivíduo apresenta sua história de vida com valores, cultura, significados, razões, propósitos e objetivos próprios. Cada pessoa apresenta uma perspectiva de vida (uma forma de pensar), com seus próprios pressupostos. Percebe-se então que para escutar é de extrema relevância aprender a suspender nossos pressupostos, tentando atenuar os nossos condicionamentos, para que não deixemos nos levar por uma visão de mundo estreitada e obscurecida. Sempre que nos defrontamos com uma ideia ou situação nova, nossa tendência é compará-la de imediato com nossos referenciais. Logo, acreditamos que a fixação em determinadas ideias constitui o principal motivo de nossa resistência para escutar o outro ${ }^{(3)}$.

Dessa forma, considera-se que escutar seja uma maneira de examinarmos a ampla experiência humana, ou seja, nossos valores, a intensidade de nossas emoções, os padrões de nossos processos de pensamento, bem como, compreender e modificar nossa visão de mundo fragmentada, uma vez que temos à tendência a limitarmos a nossos pensamentos ${ }^{(4)}$. Essa maneira fragmentada de pensarmos e, consequentemente, de escutarmos, deve-se ao paradigma vigente (cartesiano), que apresenta uma perspectiva técnica, individualista e de descrédito em valores humanísticos. Nossa visão de mundo, alicerçada nos referenciais mecanicistas desse paradigma, tem como princípio a redução, que leva naturalmente a um processo de cegueira, e conduz a excluir tudo aquilo que não seja quantificável e mensurável, eliminado dessa forma, o elemento humano ${ }^{(5)}$.

A influência do paradigma cartesiano na área da saúde é refletida no modelo biomédico, onde é imperativa a priorização das questões biológicas, deixando de considerar a influência de outros fatores psicoemocionais e socioambientais no processo saúde-doença ${ }^{(6)}$. Esse pensamento reducionista levou à fragmentação, tanto da ciência como do homem em si, de seus sentimentos, emoções e valores. Como o paciente sente, percebe e recebe o cuidado, não é interessante ao modelo vigente e, desse modo, permanece irrelevante em relação às práticas assistenciais ${ }^{(7)}$.

A Enfermagem, profissão que também está inserida na área da saúde, organiza seu processo ensinoaprendizagem e, consequentemente, suas práticas assistenciais em torno desse modelo, levando-os muitas vezes a priorizar a doença e não a pessoa em si. Os 
profissionais de Enfermagem, enquanto restritos ao modelo biomédico, encontram-se impossibilitados de considerar a experiência do sofrimento como integrante da sua relação profissional. E, apesar da Enfermagem ter como princípio, o cuidado do indivíduo sob a perspectiva integral (biopsicossociocultural e espiritual), suas ações ficam aquém das expectativas, uma vez que, é priorizado o aspecto tecnicista ${ }^{(7)}$. Não se trata de discutir a necessidade de desenvolver a competência técnica desse profissional. Porém, há que se atentar para o desenvolvimento de habilidades, não só no agir, mas também no escutar e no sentir. Se a função precípua da Enfermagem é o cuidado ao ser humano, é necessário enfatizar a complexidade humana, focando a compreensão e o respeito ao outro, por meio de uma escuta atenta e sensível ${ }^{(8)}$.

Diante disso perguntamos: será que os pacientes internados sentem-se escutados pela equipe de enfermagem? Qual a percepção desses pacientes quanto ao ato de serem escutados pela equipe de enfermagem?

Partimos da hipótese que é fundamental que o paciente sinta-se escutado pela equipe de enfermagem, e que estes profissionais aprimorem suas relações interpessoais na tarefa assistencial, desenvolvendo sua sensibilidade para o ato de escutar. Consideramos que uma escuta sensível é essencial para compreendermos a complexidade da condição humana, e possibilitarmos uma assistência de enfermagem significativa.

Frente a estas considerações, o presente estudo objetivou verificar se os pacientes sentem-se escutados pelos profissionais de enfermagem durante o período de internação e identificar as percepções apresentadas pelos pacientes quanto à assistência de Enfermagem calcada numa escuta eficiente.

\section{MÉTODO}

Trata-se de um estudo exploratório, com metodologia qualitativa, para qual utilizamos o referencial teórico do Pensamento Complexo de Morin ${ }^{(5,9)}$ e outros autores que compartilham essa perspectiva ${ }^{(3-4,7)}$.

A pesquisa foi realizada em agosto de 2008, em uma instituição hospitalar pública de grande porte, localizada em Santo André, São Paulo. A população deste estudo foi constituída por 10 indivíduos com idade igual ou superior a 60 anos, internados por um período igual ou acima de 7 dias, de ambos os sexos e que estavam em condições de compreender e responder o que lhes era perguntado na entrevista. A escolha desta população se deu pelo aumento dessa clientela nas instituições hospitalares; o envelhecimento da população é um dos maiores triunfos da humanidade e também um dos nossos grandes desafios.

Para a coleta de dados foi utilizada a técnica de Entrevista Individual em Profundidade. Nessa técnica, o pesquisador não condiciona respostas, permitindo ao entrevistado falar livremente e com isso, descobrir as tendências espontâneas em lugar de canalizá-las. Ao mesmo tempo em que valoriza a presença do pesquisador, oferecendo todas as perspectivas possíveis para que o informante alcance a liberdade e espontaneidade necessárias, enriquecendo a investigação ${ }^{(10)}$.

Após a autorização do responsável pela instituição hospitalar pública e o parecer favorável do Comitê de Ética em Pesquisa com Seres Humanos (protocolo CEP/FMABC, registrado sob o número 161/2008) foi orientado para cada um dos participantes da pesquisa, sobre o Termo de Consentimento Livre e Esclarecido. Diante disso, foram também informados que seus nomes não seriam revelados na socialização dos dados da pesquisa. As entrevistas foram conduzidas pela questão norteadora: Você se sente escutado pela equipe de enfermagem? Fale sobre isso.

Os dados empíricos foram trabalhados por meio da Técnica de Análise de Conteúdo:

[...] um conjunto de técnicas de análise das comunicações visando obter procedimentos sistemáticos e objetivos da descrição do conteúdo das mensagens, indicadores (quantitativos ou não) que permitam a inferência de conhecimentos relativos às condições de produção/ recepção (variáveis inferidas) destas mensagens ${ }^{(11: 42)}$.

Cinco etapas foram adotadas para uma construção consistente das categorias ${ }^{(11)}$ :

$1^{\circ}$ - Após a transcrição na íntegra das entrevistas gravadas, realizou-se uma leitura flutuante dos textos. Posteriormente, procederam-se mais três releituras, intercalando a escuta do material gravado com a leitura do material transcrito. Essa postura atenta possibilitou acompanhar o encadeamento de associações em cada entrevista e entre as entrevistas. Permitiu ainda a associação o mais livremente possível a qualquer elemento do discurso. Na leitura flutuante nos deixamos invadir por impressões e orientações, antes de analisar ou conhecer o texto;

$2^{\circ}$ - Por meio de nova re-leitura, foram grifadas palavras e frases dos textos originais, identificando-se as convergências e divergências em cada entrevista; 
$3^{\circ}$ - A seguir, palavras e frases grifadas foram recortadas dos textos originais. Da mesma forma, esse procedimento deu-se em cada uma das entrevistas;

$4^{\mathrm{o}}$ - Após o recorte das palavras e frases, buscou-se identificar as convergências e divergências por entrevistas e entre as entrevistas, para a elaboração das categorias;

$5^{\circ}$ - Após a construção das categorias, procedeu-se à discussão dos dados.

\section{RESULTADOS}

As categorias encontradas foram: $O$ ato de escutar comprometido pela falta de tempo e de pessoas na equipe de enfermagem; A escuta do profissional de enfermagem: propiciando ao doente a sensação de ser compreendido; e $O$ ato de escutar com disponibilidade da equipe de Enfermagem.

\section{DISCUSSÃO}

\section{$O$ ato de escutar comprometido pela falta de tempo e de pessoas na equipe de enfermagem}

O dimensionamento constitui a etapa inicial do processo de provimento de pessoal, cuja finalidade é a previsão da quantidade de funcionários por categoria, requerida para suprir as necessidades de assistência de enfermagem, direta ou indiretamente prestada à clientela ${ }^{(12)}$. Percebe-se, dessa forma, que esse tema é muito importante e tem sido um assunto bastante discutido nos dias de hoje. Esse maior empenho pelo assunto tem ocorrido porque as instituições carecem adequar seus gastos com os profissionais de enfermagem, a uma nova situação, cujos recursos financeiros são insuficientes, necessitando aprimorar o serviço prestado ou implantar novos métodos de assistência. Lembramos que a política organizacional sofre, constantemente, influência das transformações socioculturais, políticas e econômicas que ocorrem no país e no mundo, que, por sua vez, afetam o serviço de enfermagem. Sabemos que dentro das instituições de saúde, o maior contingente de servidores é formado pelo pessoal de enfermagem. Estes representam um custo elevado para as instituições de saúde, no processo contínuo de admissão, seleção, treinamento, aperfeiçoamento e avaliação ${ }^{(13)}$.

Portanto, a questão da redução de custos quando necessário tende a recair sobre a equipe de enferma- gem, ocasionando diminuição do quadro de pessoal e/ou a não reposição de vagas, o que repercute na qualidade da assistência prestada, comprometendo por sua vez, o ato de escutar os clientes, ocasionado pelo excesso de trabalho ${ }^{(14)}$.

A Enfermagem em instituição de saúde possui o encargo de oferecer cuidado nas 24 horas do dia, a sucessivos pacientes, com diferentes patologias e graus de complexidade. Com um número reduzido de profissionais da área, temos acúmulo de tarefas práticas e lineares, uma vez que, a redução do número de profissionais, não é proporcional ao número de clientes. Essa situação é entendida pelos clientes, que justificam a falta de pessoal e, consequentemente, a falta de tempo para o ato de escutar:

Na enfermagem eles são bons [...] mas são poucos, para atender muita gente. Então, não dá pra querer que dê atenção a todos da mesma maneira. Porque eles estão super atarefados [...]. (E.1)

Tem poucos profissionais para atender toda essa ala, né? Porque sempre tem um que falta ou está de folga. Então, nessa parte aí fica um pouquinho a desejar [...]. (E.2)

Sinto-me bem tratado, atendimento de primeira [...] não os culpo por não me escutar. Não que eles sejam ruins para com a gente, mas é que o número de profissionais existentes não é o suficiente, são poucos para tantos pacientes [...]. (E.3)

Compreendemos que o dimensionamento constitui um dos instrumentos da administração indispensável para o enfermeiro, cujas informações auxiliam na função gerencial. Tem como objetivo presumir para as unidades prestadoras de serviço de saúde, pública ou privada, o número de pessoal de enfermagem, sob o aspecto quantitativo e qualitativo, apto a atender às necessidades de assistência da clientela ${ }^{(15)}$. Ressalta-se ainda que o enfermeiro, seja ele assistencial, supervisor ou diretor, traz de sua formação, além do conhecimento clínico e de saúde coletiva, um elemento administrativo. Cabe a esse profissional desenvolvê-lo, adquirindo aptidões e capacidades para discuti-lo diante dos seus subordinados, pares e superiores hierárquicos, sejam esses da enfermagem ou profissionais de outra formação.

Por meio desta categoria, podemos entender que o ato de escutar está comprometido pela falta de pessoas e de tempo pela equipe de enfermagem, ficando em 
segundo plano, a necessidade do paciente ser ouvido nessa fase que se encontra fragilizado pela doença e todas as conseqüências que ela traz. Dessa forma, refletir o gerenciamento de serviço de enfermagem e o dimensionamento de pessoal é uma tarefa fundamental, desde que seja agregada a importância, não só em tarefa concretas, no agir, mas também no ouvir e no sentir. Focar a compreensão e o respeito ao outro, por meio de uma escuta atenta e sensível, também faz parte do cuidado em Enfermagem.

\section{A escuta do profissional de enfermagem: propician- do ao doente a sensação de ser compreendido}

Para o profissional de enfermagem é essencial que haja a incorporação do aprendizado e do aprimoramento dos aspectos interpessoais da tarefa assistencial, para que esses possam conhecer os fenômenos psicológicos que nela atuam ${ }^{(16)}$. É de grande importância, utilizar e desenvolver a sensibilidade, para conhecer a realidade do cliente, escutar suas queixas e encontrar, junto com ele, estratégias que facilitem sua aceitação e compreensão da doença, contribuindo para a adaptação e modificações que porventura, tenha que fazer por conta de seu problema ${ }^{(16)}$.

Diante dos trechos das falas selecionadas a seguir, percebemos que apesar do número reduzido de profissionais de enfermagem e da falta de tempo por parte deles, já discutidos na categoria anterior, os pacientes associam o ato de serem escutados com o fato de se sentirem compreendidos, traduzidos pelo bom atendimento e tratamento:

São muito atenciosos [equipe de enfermagem]. Fazem o trabalho deles direitinho [...]. (E.4)

Aqui somos tratados maravilhosamente bem. Eles [equipe de enfermagem] vêm aqui no quarto conversar com a gente, medicar, tudo direitinho. Porque eles tratam bem a gente [...]. (E.5)

O vínculo profissional-cliente é elemento fundamental, deve existir como mola propulsora de um bom atendimento e tratamento de saúde. A técnica por mais aprimorada que seja, tenderá a ser inócua ou alienante, se não for veiculada por uma boa relação entre profissional e paciente. Sabe-se que há considerável alívio e melhoria das condições do trabalho assistencial quando o profissional pode conhecer, por um lado, os motivos do comportamento do cliente e, por outro, tanto os efeitos que esse comportamento lhe provoca (tais como angústia, raiva, impotência) como as defesas que desencadeia. Muitas queixas e problemas dos usuários podem ser resolvidos ou atenuados quando estes se sentem compreendidos e respeitados pelos profissionais. A falta de acolhimento ao cliente e de suas continências referente aos seus aspectos emocionais pode conduzir ao abandono ou a não adesão ao tratamento ${ }^{(16)}$.

Por meio desta categoria, podemos entender que o ato de escutar está relacionado com o fato dos pacientes sentirem-se compreendidos. Associam o reflexo dessa compreensão, com o bom atendimento e tratamento de saúde, que por sua vez, se fundamenta em uma série de quesitos, entre eles instalações e equipamentos adequados, garantia da privacidade do cliente, informações satisfatórias sobre o que realmente está ou irá acontecer com o paciente, ética por parte dos profissionais, bem como o respeito pelas diferenças, à atenção dispensada pelos profissionais.

\section{O ato de escutar com disponibilidade da equipe de enfermagem}

Escutar é um ato consciente que exige atenção e abertura, sendo necessário estar disposto e atento para tal atividade. Assim, nossa predisposição, que pode ser vista por meio do nosso comportamento, irá dar maior ou menor eficiência a esse ato. Podemos dizer também, que fatores físicos como a temperatura, o ruído, a iluminação, o meio ambiente e as condições de saúde, bem como, fatores mentais, como a indiferença, a impaciência, o preconceito e a preocupação, podem interferir na qualidade da escuta. Entretanto, é o objetivo em mente que irá determinar a maneira de escutar, graduando interesses, estímulos e reações individuais ${ }^{(17)}$.

Para ser um bom ouvinte é necessário estar predisposto a escutar o outro, dispondo de nosso tempo e da nossa disposição interna. Precisamos abrir mão da nossa propensão em falar e nos habituarmos a não interromper a qualquer pretexto as pessoas que estão nos falando ${ }^{(3)}$.

Diante disso, é necessário suspender nossas ideias prévias. Porém, o ser humano não está habituado a fazer temporariamente suspensões de seus pressupostos, pois, este foi ensinado e condicionado a dar respostas imediatas e impulsivas. Para que possamos, escutar com a finalidade de compreender e enriquecer nosso referencial de conhecimentos é preciso estar atento aos nossos sentimentos e pensamentos, e conseqüente- 
mente, passaríamos a escutar o outro verdadeiramente, conhecendo também, o que pensam e sentem ${ }^{(4)}$.

Oferecer uma escuta sensível ao paciente é tentar compreendê-lo em sua condição humana ${ }^{(3)}$. A compreensão é um conhecimento empático das atitudes, sentimentos, intenções e finalidades dos outros, considerando que é um fruto de uma mimese psicológica que permite reconhecer ou mesmo sentir o que sente o outro ${ }^{(5)}$. O trecho selecionado a seguir demonstra a importância e a necessidade do paciente em ser escutado com sincera disponibilidade por parte da equipe de enfermagem:

É difícil encontrar alguém com o coração aberto para nos escutar aqui... Abrir o coração não é algo de se jogar fora [...]. Agora, estar de coração aberto para escutar o que alguma outra pessoa venha te contar, não se preocupando com o que os outros irão pensar, é maravilhoso [...]. Sem julgamento em relação ao que estou falando, simplesmente escutar. Essa relação de escutar de coração aberto na enfermagem devia ocorrer sempre [...] porque eu estou aqui praticamente amarrado na cama. É difícil encontrar alguém com o coração aberto para nos escutar [...]. (E.10)

Quando nos habituamos a escutar o outro, construímos a habilidade de compreendê-lo, pois este ato exige de quem ouve associar-se a quem fala, e viceversa. E, aprender a escutar até o final sem concordar, ou discordar de imediato, é uma postura de respeito ao outro. No entanto, concordar nem sempre significa que devemos nos colocar a mercê das opiniões e preconceitos do outro, da mesma forma, discordar não significa que devemos nos colocar a mercê de nossas próprias opiniões e preconceitos. É evidente que a capacidade de escutar sem discordar nem concordar de imediato, pode ser aprendida, embora não seja um processo fácil ${ }^{(3)}$.

Por meio desta categoria, podemos dizer que o ato de escutar não é uma tarefa fácil para as pessoas de um modo geral, não somente para a equipe de Enfermagem, pois precisamos ter disponibilidade interna para essa ação, que por sua vez, faz-nos refletir sobre a nossa forma de pensar e de suspender nossas ideias pré-definidas. Nossos pressupostos que acabam surgindo nos diálogos, que são nossas crenças e aparentes certezas, teorias de como o mundo deve ser, incluindo também, nossos preconceitos, hábitos de pensamentos a que nos apegamos é que dificultam, muitas vezes, a execução de uma escuta efetiva e sensível ${ }^{(4)}$.

\section{CONSIDERAÇÕES FINAIS}

Primeiramente, é importante resgatar que a iniciativa para a realização do presente estudo foi a necessidade de investigação para verificar se os pacientes sentem-se escutados pelos profissionais de enfermagem e identificar as percepções apresentadas pelos pacientes quanto à assistência de Enfermagem calcada numa escuta atenta e sensível.

Após seu término, o estudo nos mostrou que os pacientes reconhecem que a equipe de enfermagem apresenta número reduzido de profissionais, uma vez que não é proporcional ao número de clientes. Essa situação é entendida pelos clientes, e consequentemente, há falta de tempo do profissional para o ato de escutar. Entretanto, apesar desse reconhecimento, os pacientes associam o ato de serem escutados com o fato de se sentirem compreendidos, traduzidos pelo bom atendimento e tratamento. Muitas queixas e problemas dos usuários podem ser resolvidos ou atenuados quando estes se sentem compreendidos e respeitados pelos profissionais. A falta de acolhimento ao cliente e de continências aos seus aspectos emocionais pode conduzir ao abandono ou à não adesão ao tratamento.

Podemos dizer que o ato de escutar não é uma tarefa fácil para as pessoas de um modo geral, não somente para a equipe de Enfermagem, pois precisamos ter disponibilidade para essa ação, que por sua vez, faz-nos refletir sobre a nossa forma de pensar e de suspender nossas idéias pré-definidas.

Temos clareza que este tema exige reflexão e não se esgota com esse trabalho. Dessa forma, novos estudos poderão ser elaborados num modo de continuarmos a investigação, com a finalidade de aprofundar os resultados apresentados nesta pesquisa.

\section{REFERÊNCIAS}

1. Cardoso LM. Da experiência do escutar/dizer do psicólogo - na narratividade daqueles que dela partilham - a um sentido clínico atual apontado [dissertação] Recife (PE): Universidade Católica de Pernambuco; 2004.

2. Ferreira ABH. Novo Aurélio século XXI. Rio de Janeiro: Nova Fronteira; 1999.

3. Mariotti H. As paixões do ego: complexidade, política e solidariedade. São Paulo: Palas Athena; 2000.

4. Bohm D. Diálogo: comunicação e redes de convivência. 
São Paulo: Palas Athena; 2005.

5. Morin E. A cabeça bem-feita: repensar a reforma, reformar o pensamento. Rio de Janeiro: Bertrand Brasil; 2002.

6. Camillo SO. Um olhar complexo sobre o processo ensino-aprendizagem em um curso de graduação em enfermagem. [dissertação] São Paulo (SP): Secretaria do Estado da Saúde São Paulo; 2004.

7. Camillo SO, Silva AL. Inovação no ensino superior em enfermagem. São Paulo: Cabral Editora e Livraria Universitária; 2006.

8. Camillo SO, Silva AL, Nascimento AJ. Percepções do graduando de enfermagem sobre a dimensão humana no seu aprendizado. Rev. Latino-Am. Enfermagem. 2007;15(2):207-13.

9. Morin E. Ciência com consciência. Rio De Janeiro: Bertrand Brasil; 2002.

10. Triviños ANS. Introdução à pesquisa em ciências sociais: a pesquisa qualitativa em educação. São Paulo: Atlas; 1995.

11. Bardin L. Análise de conteúdo. Edições 70: Lisboa; 1977.

12. Kurcgant P. Administração em enfermagem. São Paulo: EPU; 1991.

13. Antunes AV, Costa MN. Dimensionamento de pessoal de enfermagem em um Hospital Universitário. Rev. Latino-Am. Enfermagem. 2003;11(6):832-9.

14. Campos LF, Melo MRAC. Dimensionamento de pessoal de enfermagem nos hospitais de Ribeirão Preto- SP. Cogitare enferm. 2007;12(2):253-5.

15. Gaidzinski RR. Dimensionamento de pessoal de enfermagem em instituições hospitalares [tese]. São Paulo (SP): Universidade de São Paulo; 1998.

16. Nogueira Martins MCF. Humanização das relações assistenciais: a formação do profissional de saúde. São Paulo: Casa do Psicólogo; 2001.

17. Penteado JRW. Técnica da comunicação humana. São Paulo: Pioneira; 1969. 